\title{
Mujeres, revistas latinoamericanas y lectura en la primera mitad del siglo $\mathrm{XX}^{1}$
}

\section{Women, Reading, and Latin American Magazines in the First Half of the 20th century}

\author{
CLAUDIA DARRIGRANDI NAVARRO \\ ANTONIA VIU BOTTINI \\ Universidad Adolfo Ibáńez, Facultad de Artes Liberales. Chile. \\ Correo electrónico: claudia.darrigrandi@uai.cl \\ Universidad Adolfo Ibáńez, Facultad de Artes Liberales. Chile. \\ Correo electrónico: antonia.viu@uai.cl
}

Con la publicación del dossier "Mujeres, revistas latinoamericanas y lectura en la primera mitad del siglo XX" queremos contribuir al trabajo que se ha estado realizando hace un par de décadas en torno a la inserción de las mujeres latinoamericanas en el campo cultural, por medio de una reflexión acotada a las revistas, un medio que ha ocupado un lugar central en historia de la cultura impresa del continente americano. En este dossier visibilizamos las revistas latinoamericanas de la primera mitad del siglo XX en tanto soportes para la lectura femenina y en tanto espacios creativos y de formación intelectual y profesional para ellas. Examinamos las formas de aparición de las mujeres dentro de las revistas desde variados puntos de vista: aquellas que participan y toman decisiones en tanto editoras, las que participan en labores de producción y las que enviaron sus escritos y colaboraciones. Además, buscamos dar un lugar a las mujeres como lectoras y como asunto de nuevas secciones y contenidos de prensa.

En el ejercicio de interrogarnos por la relación entre mujeres, revistas y lectura, estalla una red de vínculos y asociaciones que invitan a pensar en el papel de las mujeres en

\footnotetext{
${ }^{1}$ Este dossier se ha realizado en el marco de las investigaciones de los proyectos Fondecyt Regular No 1190499 , No 1190182, y el proyecto Redes 180157 (PCI-CONICYT). Agradecemos a Cielo Erika Ospina (Universidad de Chile) por su colaboración en la búsqueda y selección de imágenes. Las imágenes con las que trabajamos integran una cápsula desarrollada por las autoras de este artículo y Cielo Erika Ospina para Memoria Chilena. La cápsula se puede revisar en http://www.memoriachilena.cl/602/w3-article-542818.html
} 
el campo cultural desde nuevas miradas. Autoras, editoras y lectoras son las protagonistas de este dossier, lo que acredita, en parte, la relevancia de las mujeres como agentes del desarrollo de la cultura impresa latinoamericana; sin embargo, esta identificación de roles pareciera simplificar y segmentar un actuar que fue mucho más diverso y creativo de lo que se cree hasta ahora.

Desde otra arista, los conceptos de mujer, revistas y lectura implican, cada uno en su propia dimensión, una trayectoria en tanto objeto de estudio con sus propios debates epistemológicos, asunto que complejiza la discusión. Desde la perspectiva de la historia de las mujeres y de los estudios de género, la pregunta por la visibilización de las mujeres en el espacio público en tanto agentes culturales y sujetos políticos ha sido central, así como la pregunta por la representación y circulación textual e iconográfica de los cuerpos femeninos en la prensa y por sus posibilidades de construir una subjetividad o de producir otras nuevas. Es así que este ámbito constituiría una primera entrada para pensar en las colaboraciones de cada una de las propuestas críticas que integran este dossier.

Por su parte, la historiografía de las revistas en tanto prensa periódica había sido pensada, hasta hace muy poco tiempo solo desde criterios masculinistas, omitiendo la prensa dirigida por mujeres. Esta prensa editada y gestionada por mujeres, muchas veces orientada a mujeres, desestabiliza periodizaciones y categorías establecidas a partir de la prensa hegemónica. La prensa de mujeres abre otras temporalidades y tematiza el espacio privado para convertirlo en un espacio político. Asimismo, las revistas, sean dirigidas por mujeres u hombres, han sido estudiadas desde una multiplicidad de dimensiones que siguen presentes en los estudios que componen este dossier desde variados énfasis: como fuentes documentales, como medios para vehiculizar ideas o forjar comunidades lectoras y como artefactos culturales que reclaman su propia autonomía en tanto que sus materialidades proponen nuevos regímenes de visualidad y nuevos pactos de lectura. Por último, la ampliación de la noción de lectura, el entenderla como una práctica cultural y social, que implica cuerpos y afectos, y no solamente procesos cognitivos, sería otro de los elementos a tener en cuenta para los objetivos de este dossier, en tanto que al considerarla una práctica situada se imbrican lectoras y lectores, espacios y soportes.

Los artículos publicados en este volumen nos llevan a transitar por distintos ámbitos geográficos y culturales: revistas de Argentina, Brasil, Chile, Puerto Rico y Venezuela. Uno de los primeros ejes que destaca es el papel de las mujeres como directoras y editoras de revistas, lo que les permitió poner en el espacio público sus demandas sociales y políticas. Lucía Stecher y Natalia Cisterna, en su artículo "Heraldo de la Mujer de Ana Roqué: estrategias de posicionamiento en la lucha sufragista puertorriqueńa" destacan que, en dicho periódico, a diferencia de la prensa dirigida por hombres, el modelo de mujer no corresponde al ángel del hogar, sino a "una sujeto dispuesta a encarar desafíos en el espacio público y a pelear por sus derechos". De este modo, la relevancia del periódico dirigido por Roqué, junto con otras iniciativas lideradas por mujeres, "constituyeron un espacio fundamental para instalar en el espacio público puertorriqueño los argumentos feministas a favor del derecho a elegir y también a ser electas". En esta misma línea se 
sitúa el trabajo de Claudia Montero, "Trayectorias de las editoras profesionales del fin del siglo XIX en Chile", el que ofrece una definición amplia para entender el oficio de la editora finisecular, partiendo de la biografía como un recurso metodológico para estudiar la profesionalización de mujeres chilenas vinculadas en la creación y gestión de revistas. Desde otro punto de vista, señala Montero que "[l]a especificidad de la acción editorial resulta necesaria de analizar ya que ilumina el nudo problemático de mujeres y profesionalización”. En este contexto, el texto explora los elementos que se barajan al momento de signar la "profesionalidad" de las editoras del fin de siglo, destacando, entre otros, el papel de la educación o formación, el ejercicio de la docencia, y de una trayectoria letrada, o la función del reconocimiento como intelectual.

Otro núcleo temático de este dossier, al cual los dos artículos mencionados recientemente también adscribirían, aunque de forma menos directa, es el de la autoría femenina. Si para el caso de Ana Roqué, estudiada por Stecher y Cisterna, la prensa fue un medio para articular el discurso feminista, en "Autorías Transoceánicas. Una baronesa en un boudoir caraqueño" Cecilia Rodríguez Lehmann se enfoca en lo que hizo posible que la Baronesa Staffe publicara en El Cojo Ilustrado (1892-1915) mientras muchas otras escritoras venezolanas no pudieron hacerlo. En palabras de la autora, es posible "leer estas inclusiones de autorías femeninas foráneas como velados procesos de exclusión y de desplazamiento más que de apertura". El origen parisino, argumenta la autora, le permitió a la Baronesa entrar en la revista como un producto importado, en el que su escritura adquirió el estatuto de mercancía de lujo. Sin embargo, ajustada a temas femeninos, de etiqueta y vinculada a la socialité popular, señala Rodríguez Lehmann que la autoría de la Baronesa fue compleja en tanto que su participación en la revista fue intervenida por los editores lo que, a su vez, implicó que la escritura de la Baronesa, expuesta en la revista, fuese objeto de otras prácticas de lectura.

Un tercer punto de vista desde el que nos podemos aproximar a este dossier es a partir de las lectoras y las mujeres cuya presencia en las revistas se articula en tanto contenido. En "¿Con qué sueñan las mujeres? La interpretación de los sueños en la revista Idilio", Andrea Kottow estudia la recepción del sicoanálisis en Argentina a través de la sección "El psicoanálisis te ayudará" de la que Gino Germani, bajo el nombre de Richard Rest, estaba a cargo. La sección, que recogía las preguntas de las lectoras sobre sus sueños era articulada por parte de Germani siguiendo el modelo de casos de Sigmund Freud y acompañada por los fotomontajes de Grete Stern. Sin embargo, señala Kottow, el uso del sicoanálisis habría sido un recurso mediático "para atraer a las lectoras de las revistas de mujeres" y si bien la revista estaba orientada a mujeres, amas de casa, de clase media, la sección funcionó tanto como un espacio conservador, acorde a la línea editorial Idilio, como un espacio liberador. Algo similar ocurre en el artículo "Imágenes de mujeres lectoras en revista Zig-Zag, 1920-1940" de Antonia Viu y Claudia Darrigrandi, en la medida en que las autoras señalan cómo las imágenes de la mujer lectoras discuten y promueven nuevos modelos de mujeres modernas. En el texto es posible identificar, a partir de un corpus de imágenes de lectoras, nuevas prácticas de lectura asociadas a mujeres modernas 
de una incipiente clase media, en muchos casos profesionales, que desestabilizan el modelo de la otrora mujer moderna -aunque todavía presente en la revista-, pero cuyo ámbito de acción es principalmente el hogar. Las imágenes permiten, además, identificar ciertos gestos y corporalidades asociados a la lectura que dan cuenta de la presencia, al menos en el papel, de nuevas mujeres autónomas y libres y de prácticas lectoras vinculadas a la eficiencia, al ocio y al trabajo.

En "'A questão feminina': revistas, afectos y mujeres en la reforma urbana de Rio de Janeiro", Natalia López hace un seguimiento de los discursos que acompañan la modernización de Río de Janeiro en las revistas Kosmos y Renascença. Aunque la presencia de las autoras mujeres es casi inexistente, López explora el papel que se le asigna a las mujeres en un contexto positivista y de fuerte carga emocional producto de las expectativas e incertidumbres que despertaban los cambios urbanos en los primeros ańos del siglo XX. López destaca que "no es de extrañar que la questão feminina se invocara justo en el momento en que se daba inicio a los trabajos y la ciudad tenía el aspecto de un campo de batalla”. Es así que se recurrió a un cierto corpus de imágenes de mujeres que, para López, destaca la fuerza afectiva con la que se las dotó y que serviría para apaciguar la inestabilidad que suscitaba la reforma urbana. Estas fuerzas afectivas puestas de relieve por el trabajo de López están también en otras propuestas, como el análisis de las imágenes de mujeres lectoras de Darrigrandi y Viu, lo que demuestra que sin la resignificación afectiva de la lectura como práctica de ocio, descanso y autoafirmación no se explica la renovación de los modelos de la mujer moderna de estas revistas. Por otra parte, la revista como un espacio que va redefiniendo los campos de afectación de las mujeres modernas y las formas de lidiar con ellos adquiere un lugar protagónico en la sección de revista Idilio que trabaja Andrea Kottow.

Es interesante ver que los distintos trabajos del dossier aportan no solo a presentar nuevas formas de la prensa y la lectura en relación a las mujeres, sino también a ampliar los objetos de estudio incorporando una variedad de secciones en las revistas vinculadas a la mujer, como fueron "El psicoanálisis te ayudará" en revista Idilio o "El tocador de damas" en El Cojo Ilustrado. Se trata de secciones que dan clara cuenta de las maneras en las que la lectoría femenina empieza a diversificarse y constituyen un registro de la recepción de tendencias culturales como la moda parisina finisecular o la recepción del psicoanálisis en Latinoamérica. Sin duda estas secciones hablan de formas de inserción de las mujeres en la prensa, como columnistas o a cargo de consultorios de diversa índole, y van ampliando las perspectivas respecto de los espacios que integran sus trayectorias profesionales y complejizando las miradas críticas a acerca de los procesos de participación laboral y legitimación intelectual para las mujeres.

Por último, nos gustaría destacar que al multiplicar los objetos, las perspectivas y las metodologías de análisis en torno a la relación entre mujeres, lectura y prensa, el dossier apunta a visibilizar también la materialidad de las revistas y las relaciones gráficas que estas establecen entre textos, imágenes fotográficas, ilustraciones, disposiciones textuales e incluso gestualidades, por mencionar solo algunos elementos que interactúan en ellas susceptibles 
de estudiarse desde ese punto de vista, en tanto adquieren usos y sentidos específicos en las revistas. Más que un trabajo sistemático en este sentido, buscamos iluminar otros trazados posibles para el estudio de las relaciones propuestas que incorporen la materialidad de las revistas, más allá de lo referido a los aspectos de producción y circulación que suelen agotar la reflexión en este ámbito, como una dimensión significativa al articular relaciones entre mujer y prensa o mujer y lectura. 
